\title{
The Influence of Age, Location and Soil Conditions on the Allometry of Young Norway Spruce (Picea abies L. Karst.) Trees
}

\author{
Ioan DUTCA $\breve{~}^{1,2 *}$, Filofteia NEGRUT, $I^{2}{ }^{2}$, Florin IORAŞ ${ }^{1}$, Kevin MAHER ${ }^{1}$, \\ Viorel N.B. BLUJDEA ${ }^{3}$, Liviu Alexandru CIUVĂȚT, \\ ${ }^{1}$ Buckinghamshire New University, Queen Alexandra Rd, High Wycombe, Buckinghamshire HP11 2JZ, \\ UnitedKingdom; idutca@unitbv.ro (*correspondingauthor);florin.ioras@gmail.com; Kevin.Maher@bucks.ac.uk \\ ${ }^{2}$ Transilvania University of Brasov, Department of Forest Sciences, 1 Sirul Beethoven, 500123, Brasov, \\ Romania;idutca@unitbv.ro;negrutiu@unitbv.ro; alexandru.ciuvat@gmail.com \\ ${ }^{3}$ Forest Management and Research Institute, Bulevardul Eroilor 128, Voluntari, Ilfov, \\ Romania;viorel_blujdea@yahoo.com; alexandru.ciuvat@gmail.com
}

\begin{abstract}
In this study the influence of tree's age, location (i.e. latitude and altitude) and soil conditions (i.e. pH, humus content, carbon to nitrogen ratio, cation exchange capacity and percent base saturation) on tree allometry was investigated. The data was collected from 22 Norway spruce (Picea abies L. Karst) plantations located in Eastern Carpathians of Romania, aged between 4 and 15. From each plantation a soil sample and 10 trees were collected for soil chemical properties and biomass measurements, respectively. Root collar diameter (RCD) and height $(\mathrm{H})$ based allometric equations were developed for total tree and vegetative organs of the tree (i.e. stem, branches, needles and roots). Furthermore, the interaction between the standardised residuals of these models and the tested factors was analysed. In order to account for the random effect of the clustered data, the mixed-effect modelling procedure was used. The results have shown no influence of these factors (age, location and soil conditions) on RCD based models, except for branches biomass model which was linked to soil carbon/nitrogen ratio. The $\mathrm{H}$ based models, however, were significantly influenced by latitude and soil cation exchange capacity as a consequence of H/RCD ratio change with these factors. The trees were more likely to allocate more to height growth when growing in higher latitudes or on soils with higher values of cation exchange capacity.
\end{abstract}

Keywords: allometric equation, biomass, factors, mixed-effect models, soil influence

\section{Introduction}

Tree allometry, showing the relationship between easy to measure tree characteristics (e.g. tree diameter, height) and some other tree features (e.g. tree biomass) much more difficult to assess, is one of the most important tool in biomass and carbon estimations in forests (Chave et al., 2005; Olofsson et al., 2011; Blujdea et al., 2012). However, diameter at breast height is more frequently used as independent variable in allometric equations, because is less difficult to measure, compared to height, in mature forests (Zianis et al., 2005). Typical allometric equation $(d B / B=\alpha$ $\times d D / D)$ shows the distribution of relative growth rate of biomass $(d B / B)$ and the relative growth rate of diameter $(d D / D)$. More common is its integrated form $\left(B=\beta \times D^{\alpha}\right)$ where $\alpha$ (scaling exponent) shows how much faster the growth of biomass is when compared to the growth of diameter. Despite the fact that some theories (e.g. West Brown and Enquist's metabolic theory of ecology) claim an invariant scaling exponent (West et al., 1999), the empirical studies show a wide variation, between 2 and 3 (Zianis et al., 2005). Trees evolve allometric patterns which are species specific (Pretzsch, 2006) and site specific (Tremblay et al., 2012).

Despite the undoubted influence of environmental factors on forest biomass productivity and biomass allocation pattern, there is not much information about the influence of these factors on tree allometry. The changes in biomass allocation pattern are usually reflected in modifications of the allometric equations of tree components. However, these shifts of biomass from one vegetative organ to another may not affect the total biomass allometry. It has been found that biomass allocation pattern can be modified by soil type (Wolters and Stickan, 1991), altitude (Cienciala et al., 2006), precipitations (Paul et al., 2013) and light regime (Naidu et al., 1998, Kennedy et al., 2007). However, the response of the species to different environmental conditions may be not general. Urban et al. (2013) found that the allometry of Norway spruce was more sensitive to nutrient availability when compared to Douglas fir. Therefore, it is important to know how allocation changes are reflected into the allometric equations and what role have different independent variables in this context. 
In this paper we investigated the influence of tree's age, geographical location (latitude and altitude) and soil conditions (i.e. $\mathrm{pH}$, humus content, carbon to nitrogen ratio, cation exchange capacity and percent base saturation) on allometric equations of young Norway spruce trees.

\section{Materials and methods}

The measurements were conducted in 22 pure Norway spruce plantations in Eastern Carpathians of Romania. The altitude ranged between 640 and $1540 \mathrm{~m}$ above sea level and the latitude from 45.44 to 47.65 degrees, covering approximately $330 \mathrm{~km}$ on a N-S gradient. The initial planting grid was $2 \times 1 \mathrm{~m}(5,000$ seedlings/ha). The age of the trees (age of plantation plus the years spent in forest nursery) ranged between 4 and 15 years.

In each plantation a $200 \mathrm{~m}^{2}$ sample plot was delimited, all trees within this plot being measured for root collar diameter $(\mathrm{RCD})$ and height $(\mathrm{H})$. RCD was used instead of diameter at breast height as the height of the trees in this study was higher than $50 \mathrm{~cm}$. For each sample plot, the dimensions of the average size tree were calculated. Then from each stand, 10 trees with dimensions close to those of average tree were collected for biomass measurements. In total, 220 trees were collected. For each collected tree, RCD and $\mathrm{H}$ were measured on site. As trees were generally small, entire biomass was collected and dried at $80{ }^{\circ} \mathrm{C}$ until a constant weight was attained. Because the separation of needles from branches is difficult on fresh material, the branches with needles were first dried, to ease the separation of needles from wooden part of the branches and then, after separation, dried again until constant weight. For each tree, the total biomass (TB) and also the needles (ND), branches (BR), stem (ST) and roots (RT) biomass was measured.

The location (latitude and altitude) was established for each stand, using a Garmin GPSMap 62S. Soil samples were also taken from each plantation for chemical properties assessment. In each stand, in the centre of the sample plot, a soil profile was dug out and a single soil sample was taken from horizon A (from approximately $15 \mathrm{~cm}$ in depth) as most of the roots were in the first $20 \mathrm{~cm}$. A total of 22 soil samples were collected. The $\mathrm{pH}$, total humus content, carbon to nitrogen ratio $(\mathrm{C} / \mathrm{N})$, cation exchange capacity and percent base saturation were measured/calculated.

An important assumption of this study is that there is no significant correlation between the independent variables of allometric equations (i.e. RCD and $\mathrm{H}$ ) and the tested factors, except for age. If this assumption is not satisfied, the tested factor could modify the allometry without being able to account for this influence.

In order to obtain a linear regression between trees' biomass and their dimensions (i.e. RCD and $\mathrm{H}$ ), a natural logarithm transformation was employed. Using each of the two independent variable $(\mathrm{RCD}$ and $\mathrm{H})$, linear regressions were developed for each biomass category (total biomass, stem, branches, needles and roots). Further, the standardized residuals of each model were regressed against each factor, reporting the $p$-value of the slope. Because the data was collected in clusters, the observations were not independent. To subtract the effect of clustering, the Linear Mixed-Effects (LME) Models (nlme package in R) were used. Within the LME models, the standardized residuals were considered as fixed effect dependent variable, the analysed factors as fixed effect independent variable and the clusters as random effect independent variable. Therefore, the fixed effect of the factor on standardized residuals was accounted while the random effect of clustering was controlled.

The $p$-values associated with the slope of the fixed effect models (i.e. between the standardized residuals of the models and the tested factors) were further reported. For a $p$-value lower than 0.05 means, for a $95 \%$ confidence interval, the null hypothesis of the slope is rejected, therefore there is a significant slope between variables. The assumption is that if there is a significant slope between the standardized residuals of an allometric equation and a factor, that factor affects the allometric equation.

\section{Results and discussions}

The initial assumption was confirmed, therefore no significant correlations occurred between the independent variables and the factors, except for age of the trees.

The results showing the probabilities for the slope's null hypothesis of RCD based models are presented in Tab. 1. Only one model (i.e. branches biomass model: $\mathrm{BR}=f(\mathrm{RCD})$ ) presented significant slope $(p=0.0086)$ between its standardized residuals and the $\mathrm{C} / \mathrm{N}$ ratio. This model showed however the lowest adjusted $\mathrm{R}^{2}$ value (i.e. 0.970 ). All the other models based on RCD presented higher degrees of explained variance (i.e. higher adjusted $\mathrm{R}^{2}$ values than 0.985 ). Therefore, as the RCD explains more than $98.5 \%$ of the variance of biomass it becomes less likely for the external factors to influence the models.

The relationship between the standardized residuals of $\mathrm{BR}$ $=f(\mathrm{RCD})$ model and the $\mathrm{C} / \mathrm{N}$ ratio show a positive relationship (Fig. 1). As the $\mathrm{C} / \mathrm{N}$ ratio increases, the

Tab. 1. The p-values of the null hypothesis of the slope between standardized residuals (of RCD based biomass models) and the tested factors

\begin{tabular}{lccccc}
\hline \multirow{2}{*}{ Factors } & \multicolumn{5}{c}{$p$-values of the slope between tested factors and residuals of: } \\
\cline { 2 - 6 } & $\mathrm{TB}=\mathrm{f}(\mathrm{RCD})$ & $\mathrm{RT}=\mathrm{f}(\mathrm{RCD})$ & $\mathrm{ST}=\mathrm{f}(\mathrm{RCD})$ & $\mathrm{BR}=\mathrm{f}(\mathrm{RCD})$ & $\mathrm{ND}=\mathrm{f}(\mathrm{RCD})$ \\
\hline Stand age & 0.3073 & 0.1651 & 0.5288 & 0.7105 & 0.2042 \\
Latitude & 0.9750 & 0.7167 & 0.1570 & 0.5946 & 0.1737 \\
Altitude & 0.6180 & 0.1700 & 0.9054 & 0.7341 & 0.6707 \\
Soil pH & 0.8854 & 0.8674 & 0.7462 & 0.9889 & 0.4469 \\
Soil humus & 0.1252 & 0.3490 & 0.4160 & 0.4283 & 0.9748 \\
Soil Carbon to Nitrogen ratio & 0.1237 & 0.0951 & 0.1194 & 0.0086 & 0.1776 \\
Soil Cation Exchange Capacity & 0.1540 & 0.9221 & 0.2878 & 0.2746 & 0.0991 \\
Soil Percent Base Saturation & 0.4178 & 0.6389 & 0.8193 & 0.3890 & 0.1166 \\
\hline
\end{tabular}




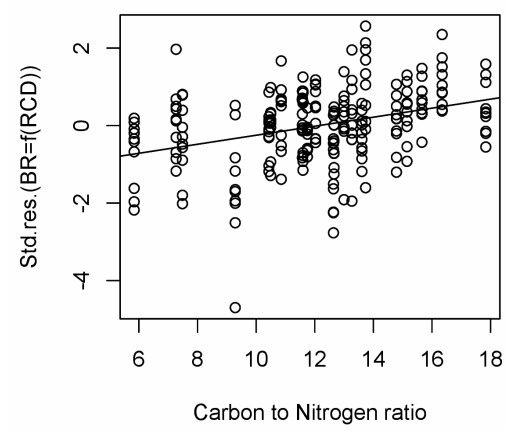

Fig. 1. Standardized residuals of $\mathrm{BR}=\mathrm{f}(\mathrm{RCD})$ model vs. $\mathrm{C} / \mathrm{N}$ ratio

standardized residuals are more likely to take positive values. In other words, for the same RCD, the trees growing on soils with higher $\mathrm{C} / \mathrm{N}$ ratio are more likely to have higher branches biomass.

The height based models presented lower values of adjusted $\mathrm{R}^{2}$ compared to $\mathrm{RCD}$ based models. The lowest value was reached by needle biomass (adjusted $\mathrm{R}^{2}=0.940$ ), followed by root biomass (adjusted $\mathrm{R}^{2}=0.942$ ), branch biomass (adjusted $\mathrm{R}^{2}=0.948$ ), total biomass (adjusted $\mathrm{R}^{2}=0.958$ ) and stem biomass (adjusted $\mathrm{R}^{2}=0.973$ ). These values are explained by the tree volume formula, as the diameter of the tree has a squared effect on tree volume (and therefore on tree biomass) compared to height (which has a linear effect). Therefore, the $\mathrm{H}$ based models, having lower degrees of explained variance are more likely to be influenced by external factors. The latitude and the soil cation exchange capacity were the factors showing significant relationship with the residuals of $\mathrm{H}$ based models (Tab. 2).

The latitude presented a significant slope with the standardized residuals of total biomass, stem and needle biomass models (significantly higher than zero). With the increase of latitude, the standardized residuals of these models take lower values (Fig. 2). This means that a tree with the same height, is more likely to have a lower biomass value in higher latitudes. These results are closely linked however with the variation of the relationship between $\mathrm{H}$ and RCD. Although not significant, the p-value (0.0853) of the slope between H/RCD ratio and latitude (Tab. 2) was close to 0.05 .

The cation exchange capacity was the factor significantly affecting all $\mathrm{H}$ based models. In Fig, 3 it is shown the way that CEC affects the models. For all biomass categories, with the
H/RCD ratio vs. CEC

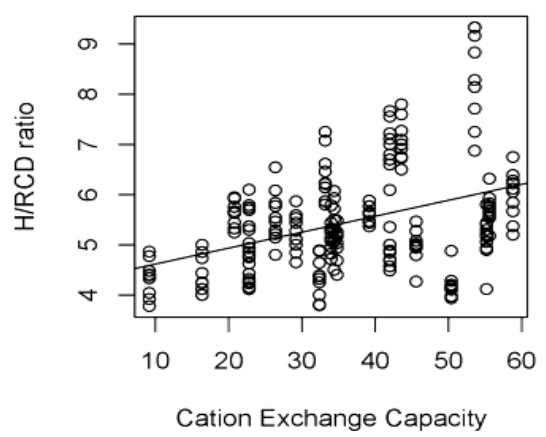

Fig. 3. The plot showing the relationship between $\mathrm{H} / \mathrm{RCD}$ ratio and CEC

increase of CEC, the value of the standardized residuals decreases. This suggests that CEC affects the shape of the trees, by making them thinner. Therefore, a tree with the same height is more likely to have lower biomass when growing on a soil with high CEC, suggesting an acceleration of height growth while the biomass allocation to diameter does not keep the pace. This is reflected in the H/RCD ratio, which is significantly affected by CEC (Fig. 3); on soils with higher CECs, the RCD is thinner for the same height, resulting in lower biomass values. The height, explaining less biomass variance compared to RCD, was more likely to have external influences.

\section{Conclusion}

The results of this study show tree diameter as a better predictor for the estimation of single tree biomass and also the biomass allocation pattern. The relationship between height and biomass was significantly affected by latitude and soil cation exchange capacity. Increasing latitude and also soil cation exchange capacity is very likely to make trees allocate more to height growth, therefore making them thinner. Therefore, this variation of growth pace between height and biomass affects tree allometry.

\section{Acknowledgments}

This work has been supported by the Romanian Ministry of Research and Education (PNII - FORLUC 31058) and The Leverhulme Trust (UK).

Tab. 2. The p-values of the null hypothesis of the slope between standardized residuals (of $\mathrm{H}$ based biomass models) and the tested factors

\begin{tabular}{lcccccc}
\hline \multirow{2}{*}{ Factor } & \multicolumn{5}{c}{$p$-values of the slope between tested factors and residuals of: } \\
\cline { 2 - 7 } & $\mathrm{TB}=f(\mathrm{H})$ & $\mathrm{RT}=f(\mathrm{H})$ & $\mathrm{ST}=f(\mathrm{H})$ & $\mathrm{BR}=f(\mathrm{H})$ & $\mathrm{ND}=f(\mathrm{H})$ & $\mathrm{H} / \mathrm{RCD}$ \\
\hline Stand age & 0.4508 & 0.3145 & 0.5752 & 0.4613 & 0.5277 & 0.0183 \\
Latitude & 0.0223 & 0.0660 & 0.0492 & 0.0657 & 0.0114 & 0.0853 \\
Altitude & 0.6061 & 0.2756 & 0.9541 & 0.6264 & 0.6411 & 0.4508 \\
Soil pH & 0.5757 & 0.5820 & 0.7663 & 0.9896 & 0.7833 & 0.9530 \\
Soil humus & 0.0683 & 0.5086 & 0.0806 & 0.2791 & 0.2716 & 0.6766 \\
Soil Carbon to Nitrogen ratio & 0.7402 & 0.9421 & 0.3460 & 0.9571 & 0.7773 & 0.8289 \\
Soil Cation Exchange Capacity & 0.0008 & 0.0111 & 0.0058 & 0.0013 & 0.0005 & 0.0010 \\
Soil Percent Base Saturation & 0.5019 & 0.6154 & 0.8037 & 0.5539 & 0.3514 & 0.9184 \\
\hline
\end{tabular}


$T B=f(H)$ vs. Latitude

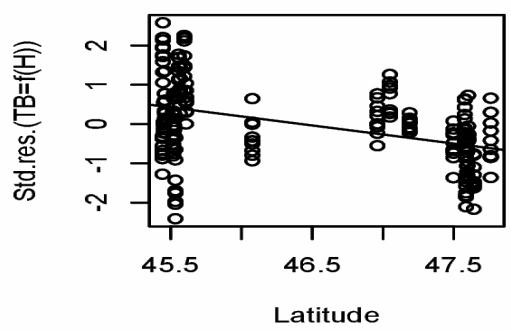

$T B=f(H)$ vs. CEC

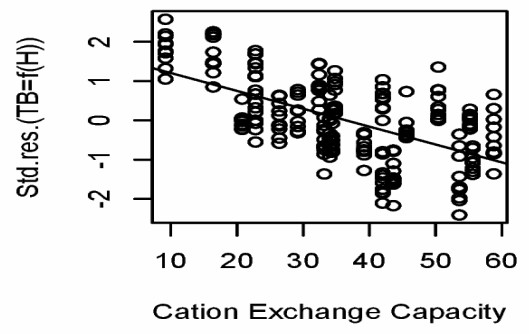

$N D=f(H)$ vs. CEC

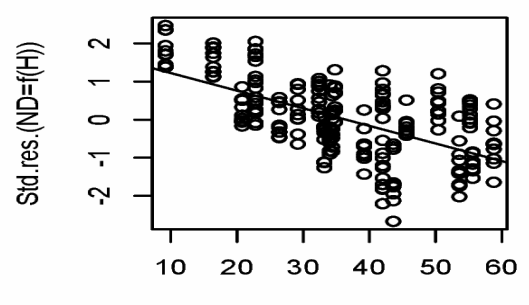

$\mathbf{S T}=\mathbf{f}(\mathrm{H})$ vs. Latitude

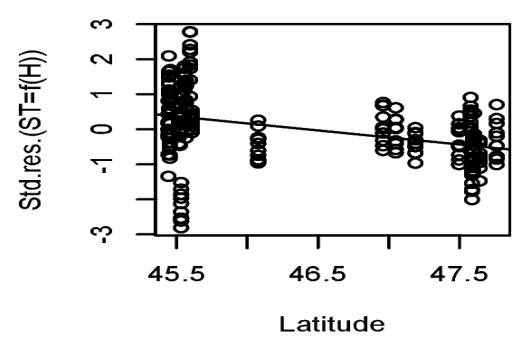

$S T=f(H)$ vs. CEC

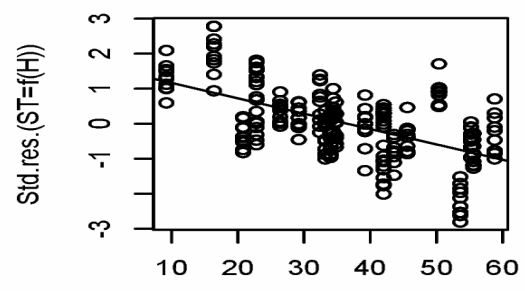

Cation Exchange Capacity

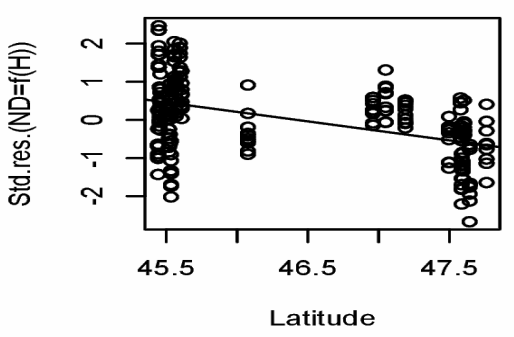

$B R=f(H)$ vs. CEC

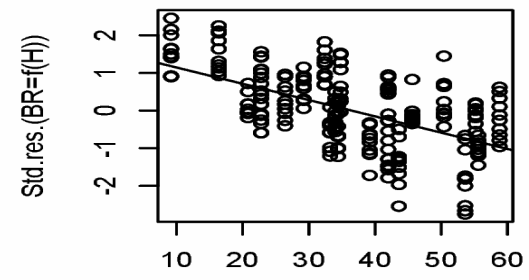

Cation Exchange Capacity

$R T=f(H)$ vS. CEC

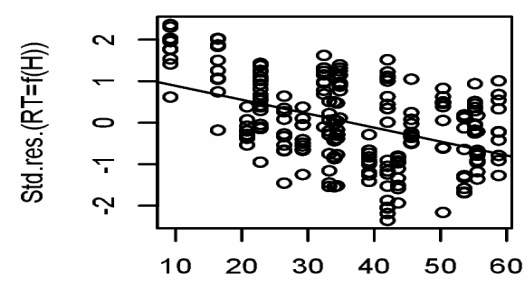

Cation Exchange Capacity

Fig. 2. Relationship of $\mathrm{H}$ based biomass models standardized residuals with latitude and CEC

\section{References}

Blujdea V, Pilli R, Dutca I, Ciuvat L, Abrudan IV (2012). Allometric biomass equations for young broadleaved trees in plantations in Romania. Forest Ecol Manag 264:172-184.

Chave J, Andalo C, Brown S, Cairns MA, Chambers JQ, Eamus D, Yamakura T (2005). Tree allometry and improved estimation of carbon stocks and balance in tropical forests. Oecologia 145(1):87-99.

Cienciala E, Černý M, Tatarinov F, Apltauer J, Exnerová Z (2006). Biomass functions applicable to Scots pine. Trees 20(4):483-495.

Kennedy S, Black K, O’Reilly C, Dhubháin ÁN (2007). The impact of shade on morphology, growth and biomass allocation in Picea sitchensis, Larixxeurolepis and Thuja plicata. New Forests 33(2):139-153.

Naidu SL, DeLucia EH, Thomas RB (1998). Contrasting patterns of biomass allocation in dominant and suppressed loblolly pine. Can J Forest Res 28(8):1116-1124.

Olofsson P, Kuemmerle T, Griffiths P, Knorn J, Baccini A, Gancz V, Blujdea V, Houghton RA, Abrudan IV, Woodcock CE (2011). Carbon implications of forest restitution in postsocialist Romania. Environ Res Lett 6(4):045202.
Paul KI, Roxburgh SH, England JR, Ritson P, et al. (2013). Development and testing of allometric equations for estimating above-ground biomass of mixed-species environmental plantings. Forest Ecol Manag 310:483-494.

Pretzsch H (2006). Species-specific allometric scaling under selfthinning: evidence from long-term plots in forest stands. Oecologia 146:572-583.

Tremblay S, Ouimet R, Houle D, Duchesne L (2012). Base cation distribution and requirement of three common forest ecosystems in eastern Canada based on site-specific and general allometric equations. Can J Forest Res 42:1796-1809.

Urban J, Holušová K, Menšík L, Čermák J, Kantor P (2013). Tree allometry of Douglas fir and Norway spruce on a nutrient poor and a nutrient-rich site. Trees - Struct Funct 27:97-110.

West GB, Brown JH, Enquist BJ (1999). A general model for the structure and allometry of plant vascular systems. Nature 400:664-667.

Wolters V, Stickan W (1991). Resource allocation of beech seedlings (Fagus sylvatica L.) relationship to earthworm activity and soil conditions. Oecologia 88(1):125-131.

Zianis D, Muukkonen P, Mäkipää R, Mencuccini M (2005). Biomass and Stem Volume Equations for Tree Species in Europe. Silva Fennica Monographs, Tampere. 